\title{
Einführung zum Dossier "Frauen und Entwicklung"
}

Frauenförderung in der Entwicklungszusammenarbeit

\section{(2) OpenEdition}

\section{Journals}

Electronic version

URL: http://journals.openedition.org/sjep/1182

DOI: $10.4000 /$ sjep. 1182

ISSN: 1663-9677

\section{Publisher}

Institut de hautes études internationales et du développement

Printed version

Date of publication: 1 janvier 1988

Number of pages: $241-242$

ISSN: 1660-5926

\section{Electronic reference}

"Einführung zum Dossier "Frauen und Entwicklung" », Schweizerisches Jahrbuch für Entwicklungspolitik [Online], 7 | 1988, Online erschienen am: 05 April 2013, abgerufen am 08 September 2020. URL : http:// journals.openedition.org/sjep/1182; DOI : https://doi.org/10.4000/sjep.1182 


\title{
Frauen und Entwicklung
}

\author{
Fravenförderung in der \\ Entwicklungszusammenarbeit
}

\section{Dle Ansätze in der Schwelz und ein Internationaler Vergleich}

Nach mehr als zwanzig Jahren Entwicklungszusammenarbeit drängt sich bei einem kritischen Rückblick die Frage auf: "Was hat die öffentliche und private Entwicklungszusammenarbeit den Frauen in der Dritten Welt gebracht ?" Erste Diskussionen zum Thema "Frauen und Entwicklung" wurden in den siebziger Jahren im Zuge der Frauenbewegung in den Industrieländern aufgenommen. Die UNO-Dekade der Frau (1975 - 1985) gab der Frauenfrage innerhalb der Entwicklungszusammenarbeit das notwendige Gewicht, um die besondere Berücksichtigung und Förderung der Frauen in den Entwicklungsländern zu einer wichtigen Forderung werden zu lassen. Frauen in Entwicklungsländern begannen ihre Probleme zu formulieren, sich zu organisieren und Selbsthilfeprojekte auf die Beine zu stellen. In Richtlinien, Resolutionen, Checklisten und Absichtserklärungen wurde die Unterstützung und Förderung der Fraven verbrieft - die Umsetzung in die Praxis verläuft jedoch nur zögernd. Die Gründe dafür sind mannigfaltig.

In einer ersten Artikelserie gehen wir der Frage nach, welche Ansätze zur Frauenförderung in der schweizerischen Entwicklungszusammenarbeit vorhanden sind oder sich abzeichnen, und wie diese Anstrengungen im internationalen Vergleich dastehen. Es werden zwei Projekte der öffentlichen Hilfe der DEH analysiert. Ein zweiter, kürzerer Beitrag skizziert die Anstrengungen der privaten Hilfswerke. Einzelne Massnahmen verschiedener privater Organisationen mit Beispielen von Frauenprojekten werden wir zu einem späteren Zeitpunkt veröffentlichen. Die Auseinandersetzung der Hilfswerke und der DEH mit dem Thema "Frauen und Entwicklung" lässt erst zögernde Ansätze einer möglichen Politik 
erkennen. Die vorliegenden Artikel sind als ein Diskussionsbeitrag innerhalb der schweizerischen Entwicklungszusammenarbeit gedacht.

Der Beitrag über die Frauenförderung in anderen Ländern ermöglicht einen internationalen Vergleich auf einem Gebiet, das noch intensiver Forschung und vermehrter öffentlicher Auseinandersetzung bedarf. Eine im September 1987 von der EADI* publizierte vergleichende Studie über die Frauenförderung in der Entwicklungszusammenarbeit in verschiedenen europäischen Ländern ist ein wichtiger Beitrag auf diesem Gebiet. Die Schweiz wird darin nicht erwähnt - ein Grund mehr, um mit vorliegendem Dossier in der Schweiz die Debatte zu diesem Thema zu eröffnen.

- EADI, European Association of Development Research and Training Institutes: Women in Development Cooperation - Europe's unfinished Business (Cecilia Andersen/lsa Baud), Antwerpen, Sept. 1987 